Research Paper

\title{
Alteration in Neuregulin 1/ERbB4 in Absence Epilepsy: Regulatory Effect on TRPV1 Expression
}

\author{
Farideh Talebi $^{1,2}$ (D), Samira Ghorbani ${ }^{2}$ (D) Leila Alizadeh $^{2}$ (D), Fatemeh Akhlaghi ${ }^{3}$ (D), Sedigheh Sadat Moeeni ${ }^{4}$ (D), Fariba Karimzadeh ${ }^{3 *}$ (iD
}

1. Immunoregulation Research Center, Shahed University, Tehran, Iran.

2. Shefa Neuroscience Research Center, Khatam Alanbia Hospital, Tehran, Iran.

3. Cellular and Molecular Research Center, Iran University of Medical Sciences, Tehran, Iran.

4. Department of Neuroscience and Addiction Studies, School of Advanced Technologies in Medicine, Tehran University of Medical Sciences, Tehran, Iran

\begin{tabular}{|c|c|}
\hline $\begin{array}{l}\text { Use your device to scan } \\
\text { and read the article online }\end{array}$ & ditation Talebi F., Ghorbani, S., Alizadeh, L., Akhlaghi, F., Sadat Moeeni, S., and Karimzadeh, F. (2022). Alteration \\
\hline 口ifirit回 & $\begin{array}{l}\text { in Neuregulin 1/ERbB4 in Absence Epilepsy: Regulatory Effect on TRPV1 Expression. Basic and Clinical Neuroscience, } \\
\text { 13(6), 777-788. http://dx.doi.org/10.32598/bcn.2021.731.2 }\end{array}$ \\
\hline alysis & dol' $h$ ttp://dx.doi.org/10.32598/bcn.2021.731.2 \\
\hline
\end{tabular}

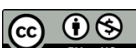

Article info:

Received: 30 Jan 2021

First Revision: 14 May 2021

Accepted: 05 Jul 2021

Available Online: 01 Nov 2022

Keywords:

Epilepsy, Cerebral Cortex, Neuregulins, Transient Receptor Potential Channels, Receptor, ErbB-4

\section{AB S T RA C T}

Introduction: The footprint of Neuregulin 1 (NRG1) / ERbB4 in the pathophysiology of some neurological disorders and TRPV1 regulation has been indicated. The alterations in NRG1 and ErbB4 as well as the TRPV1 signaling pathway were investigated during the development of absence epilepsy in the genetic animal model of absence epilepsy.

Methods: Male WAG/Rij and Wistar rats were divided into four experimental groups of two and six months of age. The protein levels of NRG1, ERbB4, and TRPV1 were measured in the somatosensory cortex and hippocampus.

Results: The cortical protein levels of NRG1 and ErbB4 in the 6-month-old WAG/Rij rats were lower than in Wistar rats. Protein levels of TRPV1 were lower in two- and sixmonth-old WAG/Rij rats compared to age-matched Wistar rats.

Hippocampal protein levels of NRG1 in 6-month-old WAG/Rij rats were lower than two-month-old WAG/Rij rats. Low levels of ErbB4 protein in two-month-old and high levels in six-month-old WAG/Rij rats were found compared to Wistar rats. Protein levels of TRPV1 were lower in the two-month-old and higher in the six-month-old WAG/Rij rats compared to age-matched Wistar rats.

Furthermore, a high correlation between NRG1/ERbB4 and TRPV1 expressions in the cortex and hippocampus was indicated. The expression of NRG1/ERbB4 and TRPV1 followed a similar pattern during the life span of Wistar and WAG/Rij rats.

Conclusion: Our findings indicated the potential role of the NRG1/ErbB4 pathway as well as TRPV1 in the pathogenesis of absence epilepsy. The regulatory effect of the ERbB4 receptor on the TRPV1 expression has been suggested following the similar pattern of expression.

* Corresponding Author:

Fariba Karimzadeh, Associate Professor

Address: Cellular and Molecular Research Center, Iran University of Medical Sciences, Tehran, Iran.

Tel: +98 (21) 86704725

E-mail: karimzade.f@iums.ac.ir 


\section{Highlights}

- The cortical protein levels of NRG1 and ErbB4 decreased during absence seizure development.

- The hippocampal protein levels of NRG1 and ErbB4 decreased during absence seizure development.

- The cortical TRPV1 down-regulated during absence seizure development.

- The hippocampal TRPV1 down-regulated during absence seizure development.

- High correlation between NRG1/ERbB4 and TRPV1 expressions was indicated.

\section{Plain Language Summary}

Finding the exact mechanisms that play critical role in the development of neurological diseases, including absence epilepsy, might lead to correct diagnosis and effective treatment of the disease. In this regard, this study has investigated the role of Neuregulin 1 (NRG1) / ERbB4 pathway and its effect on TRPV1 channel. The results of this study indicated significant reduction in the expression of (NRG1) / ERbB4 proteins as well as TRPV1 receptors in some brain areas, including the cortex and hippocampus, during absence seizures development. Also, the findings of this study showed that the expression pattern of ERB receptor is similar to the expression pattern of TRPV1 receptor. Therefore, it might be concluded that the NRG1) / ERbB4 pathway plays a notable role in the modulation of TRPV1 expression.

\section{Introduction}

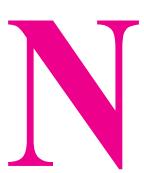

euregulin 1 (NRG1) /ErbB4 signaling is one of the essential pathways to developing the central and peripheral nervous system. The role of this pathway to regulate neuronal migration, myelination, differentiation, cortical lamination, and synaptic plasticity has been reported in several studies (Mei \& Xiong, 2008; Nave \& Salzer, 2006). This pathway is required for brain development not in the fetal period but in adulthood and its discrepancies are involved in the pathogenesis of some neurodevelopmental disorders (Mei \& Xiong, 2008).

In addition, some polymorphisms of NRG1 have contributed to temporal lobe epilepsy and epileptogenesis (Tan et al., 2012; Zhu et al., 2016). It is well understood that a deficit in the NRG1/ErbB4 pathway has been associated with schizophrenia in the human population and animal models (Mei \& Xiong, 2008; Moa \& Chen, 2017). In addition, some polymorphism of NRG1 has contributed to temporal lobe epilepsy and epileptogenesis (Tan et al., 2012; Zhu et al., 2016).

Absence seizures appear during childhood with different clinical manifestations (Jafarian, et al. 2013). Spontaneous and synchronous spike-wave discharges (SWDs) are the main characteristics of the electroen- cephalogram for the absence epilepsy. WAG/Rij rats have been considered the most valid genetic model of absence epilepsy. Absence seizures appear in adult WAG/Rij rats, mostly after three months of age (Karimzadeh et al., 2017). To clarify the developmental alteration of the NRG1/ ErbB4 signaling pathway and TRPV1 receptor, two stages of development were assessed. Two- and six-month-old of age have been considered as the early- and late-stage of development.

In addition, imbalances between excitatory and inhibitory receptors have a critical role in developing absence epilepsy (Zifkin, et al., 2005). NRG1 and its receptor ErbB4 regulated excitatory-inhibitory neurotransmission and sensorimotor gating (Agarwal et al., 2014). NRG1/ERbB4 pathway modulated GABAergic and dopaminergic transmission as well as glutamate in the synapses (Agarwal et al., 2014; Marenco et al., 2011). Overexpression of NRG1 disrupted excitatoryinhibitory connections and reduced synaptic plasticity (Barros et al., 2009; Penzes, et al., 2011). NRG1/ ERbB4 signaling modulated neural excitability as well as long-term potentiation (Pitcher, et al., 2008). Careful regulation of the NRG1/ErbB4 pathway preserved a critical balance between excitation and inhibition in the nervous system. ErbB4 regulated the activity of hippocampal and cortical pyramidal neurons (Buonanno, 2010; Mei \& Xiong, 2008), while dysfunction of them perturbed neuronal network activity (Fisahn, et 
al, 2009; Nason, et al., 2011), functional connectivity, and synaptic plasticity (Stefan, 2008).

Transient receptor potential vanilloid 1 (TRPV1) with permeability to $\mathrm{Ca}+2$ ions modulated neurotransmitter release and synaptic transmission (Saffarzadeh et al., 2016). Involvement of TRPV1 in the pathogenesis of some disorders, such as schizophrenia, hyperalgesia, and different kinds of epilepsy, including temporal lobe and tonic-clonic seizures has been indicated (Chahl, 2007; Chizh et al., 2007; Shamsizadeh, et al., 2016; Sun et al., 2013).

The regulatory effect of the NRG1/ERbB4 pathway on the TRPV1 function has been shown in the sensory neurons (Canetta, Luca, Pertot, Role, \& Talmage, 2011). The lack of NRG1 level was accompanied by TRPV1 deficit (Mei \& Nave, 2014). This regulatory effect derived us to evaluate the correlation between NRG1/ERbB4 and TRPV1 expression during the rat's life span. According to the role of these pathways in neuronal development and excitability regulation, this study evaluated alternation in NRG1/ERbB4 and TRPV1 expression during absence seizures development in the WAG/Rij rats.

\section{Materials and Methods}

\section{Animals}

Male WAG/Rij and Wistar rats were maintained in the animal lab with free access to food and water and $12 \mathrm{~h}$ light and dark cycle for one week and divided into four groups of two- and six-months of age ( $n=6$ in each group). The protocol of animal ethics was approved by Shefa Neuroscience Research Center.

\section{Detecting epileptic rats}

Two silver electrodes were implanted in the parietal cortex and the reference electrode was inserted into the nasal bone. Electrocortocencephalogram )ECoG( was recorded for six hours under sedated state induced by intraperitoneally (i.p.) injection of fentanyl (3 $\mu \mathrm{g} / \mathrm{kg})$, which was repeated every 20-30 min (Karimzadeh et al., 2016). Signals were amplified (EXT-02 F; NPI, Germany) and stored in a digital oscilloscope. Signals were analyzed by AxoScope 10 software. Six-monthold WAG/Rij rats were included in the study because of SWDs appearance in their ECoG (Karimzadeh et al., 2013). Two-month-old WAG/Rij rats as well as two- and six-month-old Wistar rats without any SWDs appearance in their ECoG were considered non-epileptic rats (Jafarian et al., 2015).

\section{Western blot analysis}

Tissues of the somatosensory cortex and hippocampus were manually dissected and homogenized in lysis buffer containing Tris- $\mathrm{HCl}(20 \mathrm{mM})$, EDTA $(1 \mathrm{mM})$, Triton 100X (1\%), and $1 \mathrm{mM}$ of phenylmethylsulfonylfluoride, aprotinin, pepstatin, as well as leupeptin $(1 \mu \mathrm{g} / \mathrm{ml})$. The clear supernatant was gathered and the protein concentrations were measured by Bradford's test.

The same protein concentrations were loaded in $12 \%$ SDS-polyacrylamide gel electrophoresis and separated by electro-blotted onto polyvinylidene difluoride (PVDF) membranes. Following blocking, the PVDF membranes were incubated for 3 hours at room temperature with primary antibodies against ErbB4, NRG1, TRPV1, and $\beta$ actin (1:500, Santa Cruz). PVDF was washed and incubated with a secondary antibody (HRPconjugated goat anti-mouse; 1:1000; Santa Cruz). Immunoreactivity was visible by ECL kit and exposed to X-ray film. The developed films were scanned by a BioRad scanner. The images were analyzed by the monomeric bands' data with Image J software.

\section{Statistical analysis}

All data are given as Mean \pm S.E.M and were analyzed by one-way analysis of variance (ANOVA) followed by Tukey's post hoc test. The probability values less than 0.05 were considered significant. The PASW Statistics 20 was used for statistical analysis.

\section{Results}

ECoG was monitored for 6 hours in all rats. Sixmonth-old WAG/Rij rats indicated SWDs in their ECoG were considered epileptic rats. The mean of SWDs frequency and amplitude was 5-10 Hz and 0.5$1.5 \mathrm{mV}$, respectively. Two-month-old rats (Wistar and WAG/Rij) as well as six-month-old Wistar rats with no SWDs in their ECoG had criteria to be included in the non-epileptic groups (Figure 1).

\section{Cortical protein level}

The total protein levels of NRG1, ErbB4, and TRPV1 were measured by immunoblotting in the somatosensory cortex (Figure 2A). The protein levels of NRG1 were significantly lower in the two- and six-month-old WAG/Rij rats compared to the six-month-old Wistar rats $(\mathrm{P}<0.001$, Figure $2 \mathrm{~B})$. Furthermore, the NRG1 levels of the six-month-old Wistar rats were significantly higher compared to two-month-old Wistar rats 
$(\mathrm{P}<0.001$, Figure 2B). The levels of NRG1 had no significant difference in two-month-old WAG/Rij rats compared to age-matched Wistar rats.There was no significant difference in the NRG1 levels between twoand six-month-old WAG/Rij rats.

The protein levels of ErbB4 were significantly lower in the two- and six-month-old WAG/Rij rats compared to six-month-old Wistar rats $(\mathrm{P}<0.01$, Figure $2 \mathrm{~B})$. Further, it showed a significantly lower expression in the sixmonth-old WAG/Rij rats compared to two-month-old WAG/Rij rats $(\mathrm{P}<0.01$, Figure $2 \mathrm{~B})$. The ErbB4 levels did not significantly differ between two-month-old Wistar and WAG/Rij rats. The levels of TRPV1 in two- and sixmonth-old WAG/Rij rats were significantly lower than age-matched Wistar rats $(\mathrm{P}<0.01$, Figure 2B). TRPV1 highly expressed in 6-month-old Wistar rats compared to two-month-old Wistar rats $(\mathrm{P}<0.05$, Figure $2 \mathrm{~B})$.

\section{Hippocampal protein levels}

The total protein levels of NRG1, ErbB4, and TRPV1 were measured by immunoblotting in the hippocampus (Figure 3A). The protein levels of NRG1 were significantly lower in the six-month-old WAG/Rij rats compared to two-month-old Wistar and WAG/Rij rats $(\mathrm{P}<0.01$ and $\mathrm{P}<0.05$, respectively). There was no significant difference in six-month-old WAG/Rij rats compared to age-matched- Wistar rats (Figure 3A).

The protein levels of ErbB4 were significantly lower in the two-month-old WAG/Rij rats compared to agematched Wistar rats $(\mathrm{P}<0.01$, Figure $3 \mathrm{~B})$. The ErbB4 levels were significantly higher in six-month-old WAG/ Rij rats compared to six-month-old Wistar rats $(\mathrm{P}<0.001$, Figure 3B). In addition, the ErbB4 levels were significantly lower in the six-month-old Wistar rats compared to two-month-old Wistar rats $(\mathrm{P}<0.01$, Figure $3 \mathrm{~B})$.

The levels of TRPV1 were lower in two-month-old WAG/Rij and six-month-old Wistar rats compared to two-month-old Wistar rats $(\mathrm{P}<0.001$ and $\mathrm{P}<0.01$, respectively, Figure 3B). TRPV1 highly expressed in six-month-old WAG/Rij rats compared to age-matched Wistar rats as well as two-month-old WAG/Rij rats $(\mathrm{P}<0.01$, Figure 3B).

\section{Correlation between expression of NRG1/ERbB4 and TRPV1}

The correlation between protein expression of NRG1/ ERbB4 and TRPV1 independently to rats' strain was analyzed in the somatosensory cortex and hippocampus
(Figure 4). Cortical correlation between protein levels of NRG1 and TRPV1 showed that high expression of NRG1 (Figure 4A; r=0.6), as well as ERbB4 (Figure 4B; $\mathrm{r}=0.8$ ), was accompanied by a high level of TRPV1.

Hippocampal correlation between gene and protein levels of NRG1/ERbB4 and TRPV1 showed high protein level of ERbB4 was accompanied by an increase in the TRPV1 protein expression (Figure 4D; $r=0.9$ ). There was no significant correlation between NRG1 and TRPV1 expression (Figure 4C; $r=0.04$ ).

\section{Discussion}

\section{Cortical expression}

Our findings showed the lack of NRG1/ERbB4 as well as TRPV1 expression in the somatosensory cortex of both juvenile and adult WAG/Rij rats compared to Wistar rats. The critical role of the NRG1/ ErBb4 signaling pathway and TRPV1 receptor in the development of the brain and cortical lamination has been shown (Rico \& Marín, 2011; Storozhuk, et al., 2019). During the development of the brain, NRG1 through the activation of ErbB2 and ErbB4 helped radial glia survival and normal neuronal migration in the cerebellum and cerebral cortex (Anton, Marchionni, Lee, \& Rakic, 1997). Further, the important role of TRPV1 receptors in the formation of healthy neuro-glial communication is impressive (Ramírez-Barrantes et al., 2016). TRPV1 promoted astrocyte migration in the inflammatory condition and its deficits reduced GFAP (as a specific marker for astrocytes) expression in the cortical and subcortical areas (Wang et al., 2019; Yang et al., 2019).

Multiple studies have insisted on the importance of astrocytes rather than neurons in the pathogenesis of several neurological disorders, including epilepsy (Kim, Park, \& Choi, 2019; Sidoryk-Wegrzynowicz, et al., 2011). In addition, we showed the lack of GFAP expression in the different cortical layers in the WAG/ Rij rats (Karimzadeh et al., 2017).

It seems that disturbances in the cortical expression of NRG1/ERbB4 as well as TRPV1, especially in the early stage of development might be involved in the cortical astrocyte attenuation, which has a critical role in absence seizure pathogenesis.

In addition, NRG1 is required for the balance of excitatory and inhibitory neurotransmission in the cortex (Agarwal et al., 2014). NRG1 regulated cellular properties associated with GABAergic interneurons and in- 
2 month-old Wistar

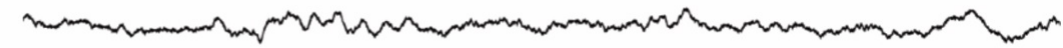

2 month-old WAG/Rij

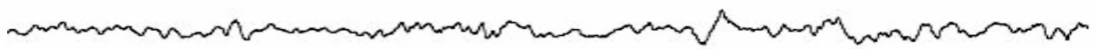

6 month-old Wistar

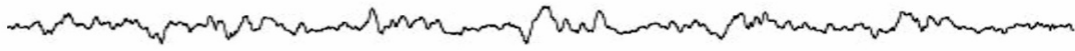

6 month-old WAG/Rij

(Epileptic rats)

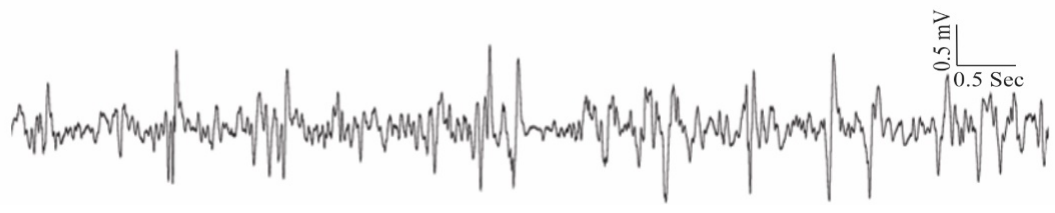

NEUR SCIENCE

Figure 1. ECoG recording of experiments. ECoG was monitored for $6 \mathrm{~h}$ to identify epileptic rats

Six-month-old WAG/Rij rats indicated spike-wave discharges (SWDs) in the ECoG and were considered the epileptic rats.

creased excitatory synaptic transmission of GABAergic interneurons in the hippocampal neurons (Longart, et al., 2004; Yau, Wang, Lai, \& Liu, 2003). NRG1 was also capable to induce the GABAa receptors in the cerebellar granular cell culture (Ozaki, Kishigami, \& Yano, 1998; Rieff et al., 1999).

The erbB4 receptor is the main signaling partner of the NRG1 signaling pathway (Birchmeier, 2009). The over-expression of the ErbB4 receptor has been shown in the cortical inhibitory interneurons of humans and primates (Neddens \& Buonanno, 2011; Rieff et al., 1999; Vullhorst et al., 2009). Cortical mRNAs of ErbB4 are expressed by dispersed GABAergic neurons (Lai \& Lemke, 1991; Woo et al., 2007).

Further, it has been reported TRPV1 modulated GABAergic synapses (Chávez, et al., 2014). It has been suggested that TRPV1 could regulate excitatory afferents to GABAergic interneurons (Ferrini, et al., 2007; Liao, et al., 2011).

It seems that cortical decrease of NRG1/ ErbB4 signaling and TRPV1 activity in the epileptic WAG/Rij rats led to a deficit in the inhibitory inputs of pyramidal cells and a decrease in GABA release from cortical interneurons. Deficits in cortical inhibitory transmis-
A

$$
\text { NRG1 }
$$
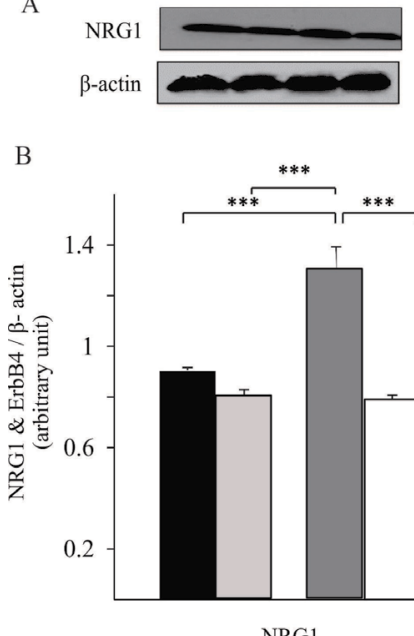

NRG1

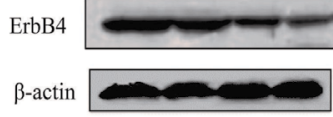

TRPV1

$\beta$-actin
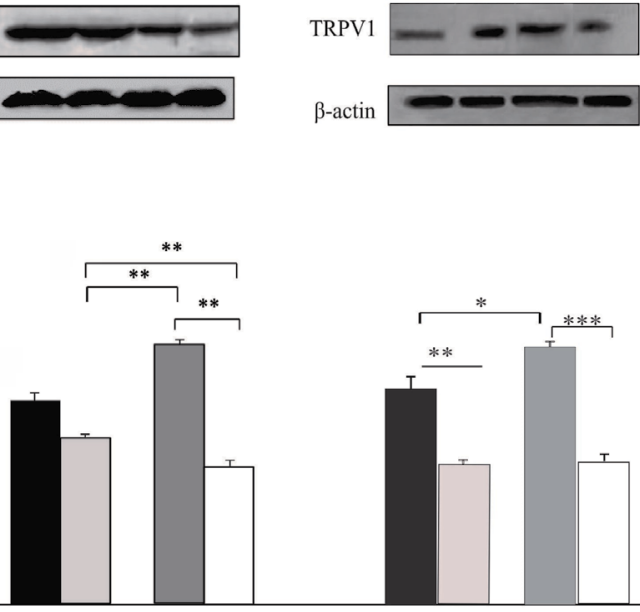

ErbB4

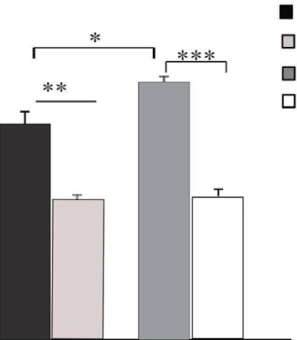

TRPV1
2 months old Wistar ๑ 2 months old WAG/Rij $\square 6$ months old Wistar 6 months old WAG/Ri

Figure 2. Immunoblotting analyses of NRG1/ErbB4 and TRPV1 of the somatosensory cortex

A: The representative immunoblot of NRG1/ ErbB4 and TRPV1 of two- and six-month-old WAG/Rij and Wistar rats is shown. B: The bar graphs indicate the quantitative results (Mean \pm SEM) of NRG1/ ErbB4 and TRPV1 protein levels in the cortex. The protein levels of NRG1/ ErbB4 and TRPV1 in two- and six-month-old WAG/Rij rats were reduced compared to Wistar rats. *, **, and *** indicate $\mathrm{P}<0.05, \mathrm{P}<0.01$, and $\mathrm{P}<0.001$, respectively. 
A
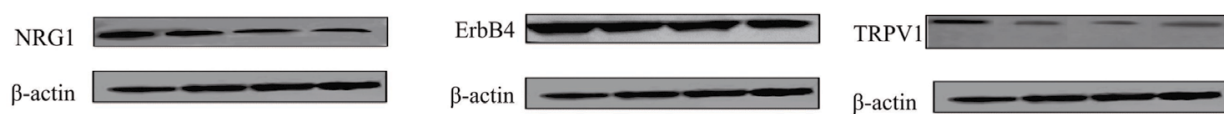

$\beta$-actin

$\beta$-actin

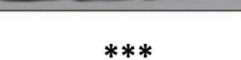

$\beta$-actin

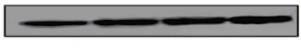

西
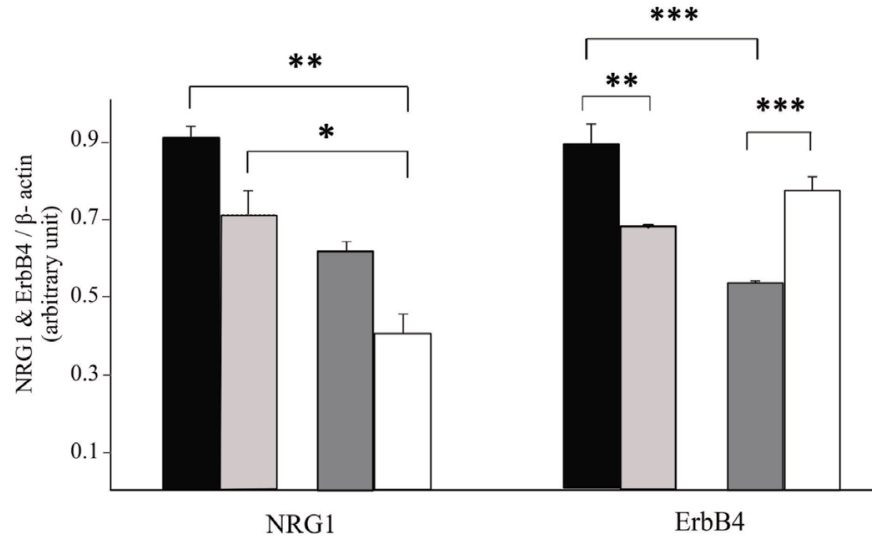

- 2 months old Wistar ㅁ 2 months old WAG/Rij $\square 6$ months old Wistar $\square 6$ months old WAG/Rij

Figure 3. Immunoblotting analyses of NRG1/ErbB4 and TRPV1 of the hippocampus

A: The representative immunoblot of NRG1/ ErbB4 and TRPV1 of two- and six-month-old WAG/Rij and Wistar rats is shown. B: The bar graphs indicate the quantitative results (Mean \pm SEM) of NRG1/ ErbB4 and TRPV1 protein levels in the hippocampus. The protein levels of NRG1 in six-month-old WAG/Rij rats decreased but the protein levels of ERbB4 and TRPV1 increased compared to age-matched Wistar rats. * ${ }^{* *}$, and ${ }^{* * *}$ indicate $\mathrm{P}<0.05, \mathrm{P}<0.01$, and $\mathrm{P}<0.001$, respectively.

sion and synapses probably trigger SWDs firings in the epileptic WAG/Rij rats.

\section{Hippocampal expression}

We showed high expression of hippocampal NRG1 / ErBb4 and TRPV1 at the early stage of Wistar rats' lifespan (two months of age) but not in WAG/Rij rats. The role of NRG1 in synaptic differentiation, such as dendritic spine size, modulation of long-term potentiation (LTP), and enhancement of entorhinal-hippocampal synaptic transmission has been reported (Kwon, et al., 2005; Li, et al., 2007; Li et al., 2014; Roysommuti, Carroll, \& Wyss, 2003; Shamir et al., 2012).

NRG1 improved cognitive impairment induced by isoflurane in aged mice (Li et al., 2014). NRG1/ ErbB4 activation compensated for the impairment of LTP induced by A $\beta 1-42$ in the hippocampal slices (Min et al., 2011). In addition, TRPV1 has a crucial role in the regulation of hippocampal synaptic transmission (Hurtado-Zavala et al., 2017). TRPV1 receptors were highly expressed in the molecular layer of the hippocampus. These cells could process inputs/outputs in the hippocampal layers (Anstötz, Lee, \& Maccaferri, 2018).

Behavior, emotional, and cognitive deficits have been indicated in children who suffer from absence epilepsy and epileptic WAG/Rij rats (Caplan et al., 2008; Jafarian et al., 2015; Masur et al., 2013). It seems that deficits of NRG1/ERbB4 as well as TRPV1 expression in the early stage of the life span of WAG/ Rij rats disrupted the development of the hippocampus and might impair memory and cognition in the adult WAG/Rij rats. In addition, hippocampal TRPV1 expression increased in adult (epileptic) WAG/Rij rats but not in adult Wistar rats. TRPV1 receptor increased seizure susceptibility in the chemical induction of seizures (Kong et al., 2014). Hippocampal expression of TRPV1 increased in the patients and animal models with mesial temporal lobe epilepsy (Gonzalez-Reyes, Ladas, Chiang, \& Durand, 2013; Sun et al., 2013).

Hippocampal glutamate release is enhanced following endogenous cannabinoid administration (GonzalezReyes et al., 2013). Activation of TRPV1 increased toxicity and cell death in dorsal root ganglions and neocortex (Olah et al., 2001; Shirakawa et al., 2008). Furthermore, we showed that ERbB4 expression increased in adult epileptic WAG/Rij rats.

Down-regulation of ErbB4 in the hippocampal interneurons improved learning and memory in the animals with genetically manipulated ErbB4 receptors (Tian et al., 2017). Enhancement of LTP in the genetically hippocampal ErbB4 deficient has been indicated (Pitcher et al., 2008). In addition, ErbB4 is selectively expressed in the hippocampal interneurons and has a regulatory effect on glutamatergic synapses in the inhibitory interneurons (Vullhorst et al., 2009). These observations showed the reciprocal role of the ERbB4 receptor in neuronal excitability as well as memory en- 


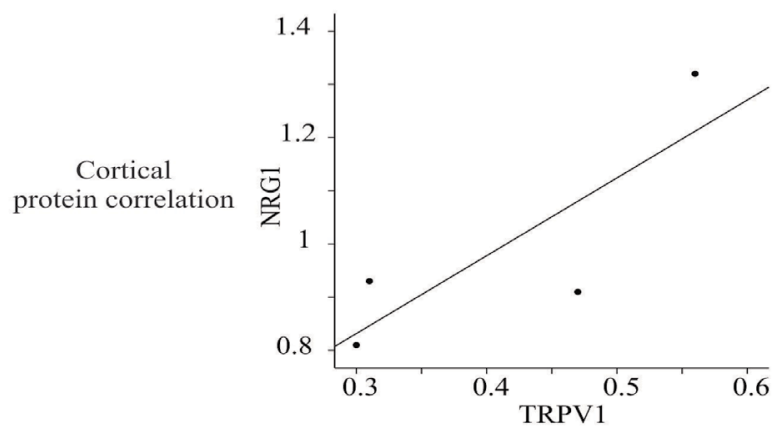

C

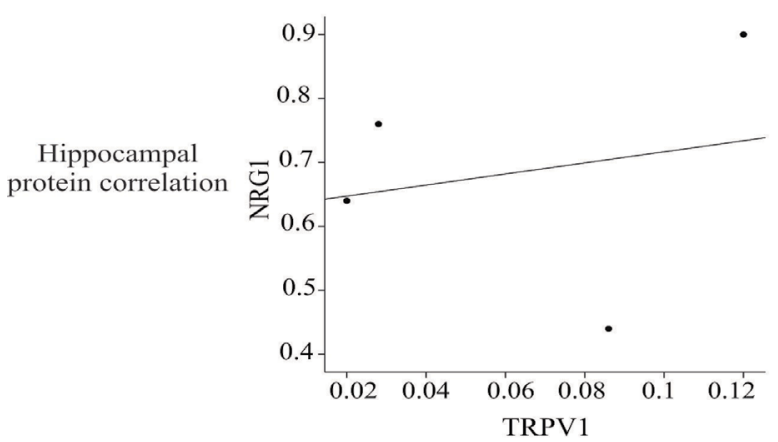

B

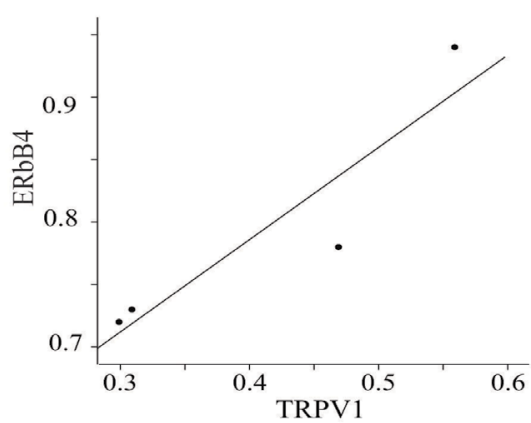

D

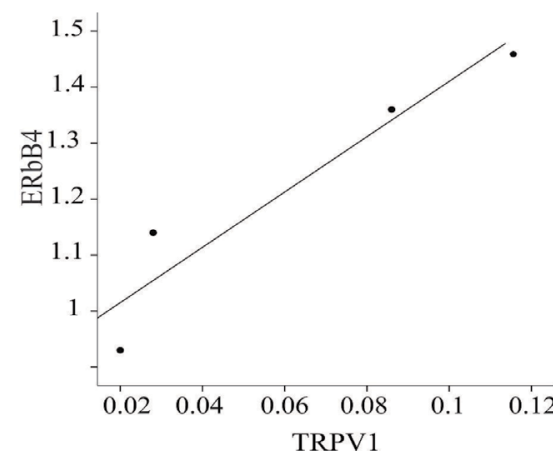

NEUR SCIENCE

Figure 4. Correlation between protein expression of NRG1/ERbB4 and TRPV1

A and B: The scatter plots indicate a correlation between the expression of NRG1/ERbB4 and TRPV1 in the somatosensory cortex. A strong correlation between protein levels of NRG1 and TRPV1 as well as ERbB4 and TRPV1 was indicated in the cortex. C and D: The scatter plots indicate the correlation between the expression of NRG1/ERbB4 and TRPV1 in the hippocampus. There was a significant correlation between protein levels of ERbB4 and TRPV1.

coding in the hippocampus. It seems that a decrease in ERbB4 expression is required for adult hippocampal function. High levels of hippocampal ERbB4, as well as TRPV1 receptor in the adult WAG/Rij rats, probably developed absence seizures in the WAG/Rij rats.

\section{Signaling correlation between NRG1/ERbB4 and TRPV1}

We showed a significant correlation between NRG1 or ERbB4 and TRPV1 expression levels in the neocortex and hippocampus. The expression of NRG1 or ERbB4 and TRPV1 follows a similar pattern during the life span of Wistar and WAG/Rij rats. An increase in NRG1 or ERbB4 expression is accompanied by high levels of TRPV1 in Wistar rats. A deficit in the NRG1 or ERbB4 expression is accompanied by a diminution of TRPV1 in WAG/Rij rats.

It is well understood that the interaction between NRG1 and ERbB receptors can facilitate cell-cell communication during the development of the brain to form healthy functional synapses (Bao, et al., 2003; Leimeroth et al., 2002).

Activation of the tyrosine kinase domain of the ERbB4 receptor leads to phosphorylation of the intracellular domain and results in the main signaling cascades downstream of NRG1/ERbB4 pathway. The mitogenactivated protein kinase (MAPK) and phosphoinositide 3-kinase (PI3K) pathways are the main downstream cascades of this signaling (Liu, et al., 2007).

NRG1 modulated the functional TRPV1 in the sensory neurons (Bao et al., 2004). Back signaling of ERbB4 enhanced TRPV1 receptors through the activation of phosphatidylinositol-3-kinase (Bao et al., 2004; Canetta et al., 2011).

It has been suggested that the activation of PI3K by NRG1 back-signaling up-regulated TRPV1 receptors. The intracellular domain of NRG1 is required to acti- 
vate PI3K and affect the TRPV1 regulation (Canetta et al., 2011). Furthermore, activation of MAPK in the injured neurons of dorsal root ganglions hyper synthesized TRPV1 receptors (Chen et al., 2016). In addition, the role of TRPV1 receptors in epileptogenesis has been reported. Cortical as well as hippocampal TRPV1 receptors are highly expressed in epileptic people suffering from temporal lobe epilepsy (Sun et al., 2013). Functional discrepancies of TRPV1 receptors altered the seizure susceptibility in the animal model of tonic-clonic epilepsy (Jia et al., 2015). In contrast, epileptogenesis was postponed by the administration of TRPV1 agonist in the kainic acid model of epilepsy (Lee et al., 2011). According to our findings, alteration in NRG1/ ERbB4 signaling pathway disturbed TRPV1 expression and possibly triggered SWDs appearance during the development of WAG/Rij rats.

\section{Conclusion}

It seems that the disturbance in the expression of Neuregulin 1 protein has a notable effect on the downregulation of ERBB4 and TRPV1 receptors. It might also be concluded that the reduction of the mentioned receptors would play an important role in the pathophysiology of absence epilepsy.

\section{Ethical Considerations}

\section{Compliance with ethical guidelines}

All experiments were performed according to the protocol approved by the ethical principles of working with laboratory animals of Iran University of Medical Sciences (IR.IUMS.REC.1396.023).

\section{Funding}

The Iran University of Medical Sciences supported this work (Grant No.: 96-01-117-30641).

\section{Authors' contributions}

Conception and design of research: Fariba Karimzadeh; Administrative, technical, and material support: Farideh Talebi, Samira Ghorbani; Perform of experiment and Acquisition of data: Leila Alizadeh, Farideh Talebi; Analysis and interpretation of data: Fatemeh Akhlaghi; Manuscript: Sedigheh Sadat Moeeni; Critical revision of the manuscript for important intellectual content: Fariba Karimzadeh.

\section{Conflict of interest}

The authors declare no conflict of interest.

\section{References}

Agarwal, A., Zhang, M., Trembak-Duff, I., Unterbarnscheidt, T., Radyushkin, K.,\& Dibaj, P., et al. (2014). Dysregulated expression of neuregulin-1 by cortical pyramidal neurons disrupts synaptic plasticity. Cell Reports, 8(4), 1130-1145. [DOI:10.1016/j.celrep.2014.07.026] [PMID]

Anstötz, M., Lee, S. K., \& Maccaferri, G. (2018). Expression of TRPV1 channels by Cajal-Retzius cells and layer-specific modulation of synaptic transmission by capsaicin in the mouse hippocampus. The Journal of Physiology, 596(16), 37393758. [PMID] [PMCID]

Anton, E. S., Marchionni, M. A., Lee, K. F., \& Rakic, P. (1997). Role of GGF/neuregulin signaling in interactions between migrating neurons and radial glia in the developing cerebral cortex. Development, 124(18), 3501-3510. [DOI:10.1242/ dev.124.18.3501] [PMID]

Bao, J., Lin, H., Ouyang, Y., Lei, D., Osman, A., \& Kim, T. W., et al. (2004). Activity-dependent transcription regulation of PSD-95 by neuregulin-1 and Eos. Nature Neuroscience, 7(11), 1250-1258. [DOI:10.1038/nn1342] [PMID]

Bao, J., Wolpowitz, D., Role, L. W., \& Talmage, D. A. (2003). Back signaling by the Nrg-1 intracellular domain. The Journal of Cell Biology, 161(6), 1133-1141. [PMID] [PMCID]

Barros, C. S., Calabrese, B., Chamero, P., Roberts, A. J., Korzus, E., \& Lloyd, K., et al. (2009). Impaired maturation of dendritic spines without disorganization of cortical cell layers in mice lacking NRG1/ErbB signaling in the central nervous system. Proceedings of the National Academy of Sciences, 106(11), 4507-4512. [PMID] [PMCID]

Birchmeier, C. (2009). ErbB receptors and the development of the nervous system. Experimental Cell Research, 315(4), 611618. [DOI:10.1016/j.yexcr.2008.10.035] [PMID]

Buonanno, A. (2010). The neuregulin signaling pathway and schizophrenia: From genes to synapses and neural circuits. Brain Research Bulletin, 83(3-4), 122-131. [PMID] [PMCID]

Canetta, S. E., Luca, E., Pertot, E., Role, L. W., \& Talmage, D. A. (2011). Type III Nrg1 back signaling enhances functional TRPV1 along sensory axons contributing to basal and inflammatory thermal pain sensation. PloS One, 6(9), e25108. [PMID] [PMCID]

Caplan, R., Siddarth, P., Stahl, L., Lanphier, E., Vona, P., \& Gurbani, S., et al. (2008). Childhood absence epilepsy: Behavioral, cognitive, and linguistic comorbidities. Epilepsia, 49(11), 1838-1846. [DOI:10.1111/j.1528-1167.2008.01680.x] [PMID]

Chahl, L. A. (2007). TRP's: Links to schizophrenia? Biochimica et Biophysica Acta, 1772(8), 968-977. [DOI:10.1016/j.bbadis.2007.05.003] [PMID]

Chávez, A. E., Hernández, V. M., Rodenas-Ruano, A., Chan, C. S., \& Castillo, P. E. (2014). Compartment-specific modulation of GABAergic synaptic transmission by TRPV1 channels in the dentate gyrus. The Journal of Neuroscience: The Official Journal of The Society for Neuroscience, 34(50), 1662116629. [PMID] [PMCID]

Chen, M., Xin, J., Liu, B., Luo, L., Li, J., \& Yin, W., et al. (2016). Mitogen-activated protein kinase and intracellular polyamine signaling is involved in TRPV1 activation-induced cardiac hypertrophy. Journal of the American Heart Association, 5(8), e003718. [PMID] 
Chizh, B. A., O'Donnell, M. B., Napolitano, A., Wang, J., Brooke, A. C., \& Aylott, M. C., et al. (2007). The effects of the TRPV1 antagonist SB-705498 on TRPV1 receptor-mediated activity and inflammatory hyperalgesia in humans. Pain, 132(1-2), 132-141. [DOI:10.1016/j.pain.2007.06.006] [PMID]

Ferrini, F., Salio, C., Vergnano, A. M., \& Merighi, A. (2007). Vanilloid receptor-1 (TRPV1)-dependent activation of inhibitory neurotransmission in spinal substantia gelatinosa neurons of mouse. Pain, 129(1-2), 195-209. [DOI:10.1016/j. pain.2007.01.009] [PMID]

Fisahn, A., Neddens, J., Yan, L., \& Buonanno, A. (2009). Neuregulin-1 modulates hippocampal gamma oscillations: Implications for schizophrenia. Cerebral Cortex, 19(3), 612-618. [PMID] [PMCID]

Gonzalez-Reyes, L. E., Ladas, T. P., Chiang, C. C., \& Durand, D. M. (2013). TRPV1 antagonist capsazepine suppresses 4-AP-induced epileptiform activity in vitro and electrographic seizures in vivo. Experimental Neurology, 250, 321332. [PMID] [PMCID]

Hurtado-Zavala, J. I., Ramachandran, B., Ahmed, S., Halder, R., Bolleyer, C., \& Awasthi, A., et al. (2017). TRPV1 regulates excitatory innervation of OLM neurons in the hippocampus. Nature Communications, 8, 15878. [PMID] [PMCID]

Jafarian, M., Karimzadeh, F., Alipour, F., Attari, F., Lotfinia, A A., \& Speckmann, E. J., et al. (2015). Cognitive impairments and neuronal injury in different brain regions of a genetic rat model of absence epilepsy. Neuroscience, 298, 161-170. [DOI:10.1016/j.neuroscience.2015.04.033] [PMID]

Jafarian, M., Karimzadeh, F., Kazemi, H., Divanbeigi, A., \& Gorji, A. (2013). [A review on absence epilepsy with focus on basic sciences (Persian)]. Razi Journal of Medical Sciences, 20(112), 24-35. [Link]

Jia, Y. F., Li, Y. C., Tang, Y. P., Cao, J., Wang, L. P., \& Yang, Y. $X$., et al. (2015). Interference of TRPV1 function altered the susceptibility of PTZ-induced seizures. Frontiers in Cellular Neuroscience, 9, 20. [PMID] [PMCID]

Karimzadeh, F., Modarres Mousavi, S. M., Alipour, F., Hosseini Ravandi, H., Kovac, S., \& Gorji, A. (2017). Developmental changes in Notch1 and NLE1 expression in a genetic model of absence epilepsy. Brain Structure and Function, 222(6), 2773-2785. [DOI:10.1007/s00429-017-1371-9] [PMID]

Karimzadeh, F., Modarres Mousavi, S. M., Ghadiri, T., Jafarian, M., Soleimani, M., \& Sadeghi, S. M., et al. (2017). The modulatory effect of metabotropic glutamate receptor type1a on spike-wave discharges in WAG/Rij rats. Molecular Neurobiology, 54(2), 846-854. [DOI:10.1007/s12035-0169692-x] [PMID]

Karimzadeh, F., Soleimani, M., Mehdizadeh, M., Jafarian, M. Mohamadpour, M., \& Kazemi, H., et al. (2013). Diminution of the NMDA receptor NR2B subunit in cortical and subcortical areas of WAG/Rij rats. Synapse (New York, N.Y.), 67(12) 839-846. [PMID]

Kim, Y., Park, J., \& Choi, Y. K. (2019). The role of astrocytes in the central nervous system focused on BK channel and heme oxygenase metabolites: A review. Antioxidants, 8(5), 121. [PMID] [PMCID]

Kong, W. L., Min, J. W., Liu, Y. L., Li, J. X., He, X. H., \& Peng, B. W. (2014). Role of TRPV1 in susceptibility to PTZ-induced seizure following repeated hyperthermia challenges in neonatal mice. Epilepsy \& Behavior, 31, 276-280. [PMID]
Kwon, O. B., Longart, M., Vullhorst, D., Hoffman, D. A., \& Buonanno, A. (2005). Neuregulin-1 reverses long-term potentiation at CA1 hippocampal synapses. The Journal of Neuroscience: The Official Journal of the Society for Neuroscience, 25(41), 9378-9383. [PMID] [PMCID]

Lai, C., \& Lemke, G. (1991). An extended family of proteintyrosine kinase genes differentially expressed in the vertebrate nervous system. Neuron, 6(5), 691-704. [PMID]

Lee, T. H., Lee, J. G., Yon, J. M., Oh, K. W., Baek, I. J., \& Nahm S. S., et al. (2011). Capsaicin prevents kainic acid-induced epileptogenesis in mice. Neurochemistry International, 58(6), 634-640. [DOI:10.1016/j.neuint.2011.01.027] [PMID]

Leimeroth, R., Lobsiger, C., Lüssi, A., Taylor, V., Suter, U., \& Sommer, L. (2002). Membrane-bound neuregulin1 type III actively promotes Schwann cell differentiation of multipotent progenitor cells. Developmental Biology, 246(2), 245-258. [DOI:10.1006/dbio.2002.0670] [PMID]

Li, B., Woo, R. S., Mei, L., \& Malinow, R. (2007). The neuregulin-1 receptor erbB4 controls glutamatergic synapse maturation and plasticity. Neuron, 54(4), 583-597. [DOI:10.1016/j. neuron.2007.03.028] [PMID]

Li, X. M., Su, F., Ji, M. H., Zhang, G. F., Qiu, L. L., \& Jia, M., et al. (2014). Disruption of hippocampal neuregulin 1-ErbB4 signaling contributes to the hippocampus-dependent cognitive impairment induced by isoflurane in aged mice. Anesthesiology, 121(1), 79-88. [PMID] [PMCID]

Liao, H. T., Lee, H. J., Ho, Y. C., \& Chiou, L. C. (2011). Capsaicin in the periaqueductal gray induces analgesia via metabotropic glutamate receptor-mediated endocannabinoid retrograde disinhibition. British Journal of Pharmacology 163(2), 330-345. [PMID] [PMCID]

Liu, Y., Tao, Y. M., Woo, R. S., Xiong, W. C., \& Mei, L. (2007). Stimulated ErbB4 internalization is necessary for neuregulin signaling in neurons. Biochemical and Biophysical Research Communications, 354(2), 505-510. [PMCID] [PMID]

Longart, M., Liu, Y., Karavanova, I., \& Buonanno, A. (2004). Neuregulin-2 is developmentally regulated and targeted to dendrites of central neurons. The Journal of Comparative Neurology, 472(2), 156-172. [DOI:10.1002/cne.20016] [PMID]

Marenco, S., Geramita, M., van der Veen, J. W., Barnett, A. S., Kolachana, B., \& Shen, J., et al. (2011). Genetic association of ErbB4 and human cortical GABA levels in vivo. The Journal of Neuroscience, 31(32), 11628-11632. [PMID] [PMCID]

Masur, D., Shinnar, S., Cnaan, A., Shinnar, R. C., Clark, P., \& Wang, J., et al. (2013). Pretreatment cognitive deficits and treatment effects on attention in childhood absence epilepsy. Neurology, 81(18), 1572-1580. [PMID] [PMCID]

Mei, L., \& Nave, K. A. (2014). Neuregulin-ERBB signaling in the nervous system and neuropsychiatric diseases. Neuron 83(1), 27-49. [PMID] [PMCID]

Mei, L., \& Xiong, W. C. (2008). Neuregulin 1 in neural development, synaptic plasticity and schizophrenia. Nature Reviews Neuroscience, 9(6), 437-452. [PMID] [PMCID]

Min, S. S., An, J., Lee, J. H., Seol, G. H., Im, J. H., \& Kim, H. S., et al. (2011). Neuregulin-1 prevents amyloid $\beta$-induced impairment of long-term potentiation in hippocampal slices via ErbB4. Neuroscience Letters, 505(1), 6-9. [DOI:10.1016/j. neulet.2011.05.246] [PMID] 
Moa, Q. C., \& Chen, J. C. (2017). Reduced neuregulin 1 expression in the medial prefrontal cortex of a rat ketamine model for schizophrenia. Neuropsychiatry, 7(4), 370-377. [Link]

Nason, M. W., Jr, Adhikari, A., Bozinoski, M., Gordon, J. A., \& Role, L. W. (2011). Disrupted activity in the hippocampalaccumbens circuit of type III neuregulin 1 mutant mice. Neuropsychopharmacology, 36(2), 488-496. [PMID] [PMCID]

Nave, K. A., \& Salzer, J. L. (2006). Axonal regulation of myelination by neuregulin 1. Current Opinion in Neurobiology, 16(5), 492-500. [DOI:10.1016/j.conb.2006.08.008] [PMID]

Neddens, J., \& Buonanno, A. (2011). Expression of the neuregulin receptor ErbB4 in the brain of the rhesus monkey (Macaca mulatta). PloS One, 6(11), e27337. [PMID] [PMCID]

Olah, Z., Szabo, T., Karai, L., Hough, C., Fields, R. D., \& Caudle, R. M., et al. (2001). Ligand-induced dynamic membrane changes and cell deletion conferred by vanilloid receptor 1. The Journal of Biological Chemistry, 276(14), 11021-11030. [PMID]

Ozaki, M., Kishigami, S., \& Yano, R. (1998). Expression of receptors for neuregulins, ErbB2, ErbB3 and ErbB4, in developing mouse cerebellum. Neuroscience Research, 30(4), 351354. [PMID]

Penzes, P., Cahill, M. E., Jones, K. A., VanLeeuwen, J. E., \& Woolfrey, K. M. (2011). Dendritic spine pathology in neuropsychiatric disorders. Nature Neuroscience, 14(3), 285-293. [PMID] [PMCID]

Pitcher, G. M., Beggs, S., Woo, R. S., Mei, L., \& Salter, M. W. (2008). ErbB4 is a suppressor of long-term potentiation in the adult hippocampus. Neuroreport, 19(2), 139-143. [PMID]

Ramírez-Barrantes, R., Cordova, C., Poblete, H., Muñoz, P., Marchant, I., \& Wianny, F., et al.(2016). Perspectives of TRPV1 function on the neurogenesis and neural plasticity. Neural Plasticity, 2016, 1568145. [PMID] [PMCID]

Rico, B., \& Marín, O. (2011). Neuregulin signaling, cortical circuitry development and schizophrenia. Current Opinion in Genetics \& Development, 21(3), 262-270. [PMID]

Rieff, H. I., Raetzman, L. T., Sapp, D. W., Yeh, H. H., Siegel, R. E., \& Corfas, G. (1999). Neuregulin induces GABAA receptor subunit expression and neurite outgrowth in cerebellar granule cells. The Journal of Neuroscience : The Official Journal of the Society for Neuroscience, 19(24), 10757-10766. [PMID] [PMCID]

Roysommuti, S., Carroll, S. L., \& Wyss, J. M. (2003). Neuregulin-1 $\beta$ modulates in vivo entorhinal-hippocampal synaptic transmission in adult rats. Neuroscience, 121(3), 779785. [PMID]

Saffarzadeh, F., Eslamizade, M. J., Mousavi, S. M., Abraki, S. B., Hadjighassem, M. R., \& Gorji, A. (2016). TRPV1 receptors augment basal synaptic transmission in CA1 and CA3 pyramidal neurons in epilepsy. Neuroscience, 314, 170-178. [PMID]

Shamir, A., Kwon, O. B., Karavanova, I., Vullhorst, D., LeivaSalcedo, E., \& Janssen, M. J., et al. (2012). The importance of the NRG-1/ErbB4 pathway for synaptic plasticity and behaviors associated with psychiatric disorders. The Journal of Neuroscience : The Official Journal of the Society for Neuroscience, 32(9), 2988-2997. [PMID]
Shamsizadeh, A., Fatehi, F., Khajehasani, F., Hassanshahi, G., \& Arababadi, M. (2016). Expression of TRPV1 receptors increased in hippocampus following pentylenetetrazoleinduced kindling in male rats. Archives of Neuroscience, 3(3), e35459. [DOI:10.5812/archneurosci.35459]

Shirakawa, H., Yamaoka, T., Sanpei, K., Sasaoka, H., Nakagawa, T., \& Kaneko, S. (2008). TRPV1 stimulation triggers apoptotic cell death of rat cortical neurons. Biochemical and Biophysical Research Communications, 377(4), 1211-1215. [PMID]

Sidoryk-Wegrzynowicz, M., Wegrzynowicz, M., Lee, E., Bowman, A. B., \& Aschner, M. (2011). Role of astrocytes in brain function and disease. Toxicologic Pathology, 39(1), 115-123. [PMID] [PMCID]

Stefan, H. (2008). Commentary on "Typical absence seizures and related epileptic syndromes: Assessment of current state and directions for future research". Epilepsia, 49(12), 2143-2144. [PMID]

Storozhuk, M. V., Moroz, O. F., \& Zholos, A. V. (2019). Multifunctional TRPV1 Ion channels in physiology and pathology with focus on the brain, vasculature, and some visceral systems. BioMed Research International, 2019, 5806321. [PMID] [PMCID]

Sun, F. J., Guo, W., Zheng, D. H., Zhang, C. Q., Li, S., \& Liu, S. Y., et al. (2013). Increased expression of TRPV1 in the cortex and hippocampus from patients with mesial temporal lobe epilepsy. Journal of Molecular Neuroscience, 49(1), 182-193. [PMID]

Tan, G. H., Liu, Y. Y., Hu, X. L., Yin, D. M., Mei, L., \& Xiong, Z. Q. (2011). Neuregulin 1 represses limbic epileptogenesis through ErbB4 in parvalbumin-expressing interneurons. Nature Neuroscience, 15(2), 258-266. [PMID]

Tian, J., Geng, F., Gao, F., Chen, Y. H., Liu, J. H., \& Wu, J. L., et al. (2017). Down-regulation of neuregulin1/ErbB4 signaling in the hippocampus is critical for learning and memory. Molecular Neurobiology, 54(6), 3976-3987. [DOI:10.1007/s12035016-9956-5] [PMID]

Vullhorst, D., Neddens, J., Karavanova, I., Tricoire, L., Petralia, R. S., \& McBain, C. J., et al. (2009). Selective expression of ErbB4 in interneurons, but not pyramidal cells, of the rodent hippocampus.The Journal of Neuroscience: The Official Journal of the Society for Neuroscience, 29(39), 12255-12264. [PMID] [PMCID]

Wang, X., Yang, X. L., Kong, W. L., Zeng, M. L., Shao, L., \& Jiang, G. T., et al. (2019). TRPV1 translocated to astrocytic membrane to promote migration and inflammatory infiltration thus promotes epilepsy after hypoxic ischemia in immature brain. Journal of Neuroinflammation, 16(1), 214. [DOI:10.1186/s12974-019-1618-x]

Woo, R. S., Li, X. M., Tao, Y., Carpenter-Hyland, E., Huang, Y. Z., \& Weber, J., et al. (2007). Neuregulin-1 enhances depolarization-induced GABA release. Neuron, 54(4), 599-610. [PMID]

Yang, X. L., Wang, X., Shao, L., Jiang, G. T., Min, J. W., \& Mei, X. Y., et al. (2019). TRPV1 mediates astrocyte activation and interleukin-1 $\beta$ release induced by hypoxic ischemia (HI). Journal of Neuroinflammation, 16(1), 114. [DOI:10.1186/ s12974-019-1487-3]

Yau, H. J., Wang, H. F., Lai, C., \& Liu, F. C. (2003). Neural development of the neuregulin receptor ErbB4 in the cerebral cortex and the hippocampus: preferential expression by interneurons tangentially migrating from the ganglionic eminences. Cerebral Cortex, 13(3), 252-264. [PMID] 
Zhu, W. Y., Jiang, P., He, X., Cao, L. J., Zhang, L. H., \& Dang, R. L., et al. (2016). Contribution of NRG1 gene polymorphisms in temporal lobe epilepsy. Journal of Child Neurology, 31(3), 271-276. [DOI:10.1177/0883073815589757] [PMID]

Zifkin, B., Andermann, E., \& Andermann, F. (2005). Mechanisms, genetics, and pathogenesis of juvenile myoclonic epilepsy. Current Opinion in Neurology, 18(2), 147-153. [PMID] 
This Page Intentionally Left Blank 